\title{
Vulture populations in Uganda: using road survey data to measure both densities and encounter rates within protected and unprotected areas
}

\author{
DEREK POMEROY, PHIL SHAW, MICHAEL OPIGE, GEORGE KAPHU, \\ DARCY L. OGADA and MUNIR Z. VIRANI
}

\begin{abstract}
Summary
Six out of seven vulture species whose global ranges lie largely or wholly within Africa are listed as globally threatened. Since their current distributions individually span up to 39 range states there is a pressing need to develop robust, standardised methods that provide a clear measure of range-wide changes in abundance. Yet, survey methods currently used tend to yield either of two measures: estimates of breeding density, derived mainly from nest counts; or linear encounter rates, derived from road surveys. Here, we present the results of a six-year survey of six vulture species in Uganda, in which we used road counts, in combination with Distance sampling, to determine both encounter rates and densities within protected areas (PAs), and in predominantly pastoral and agricultural areas. In combination, five scavenging species were detected 4-6 times more frequently in PAs than elsewhere, and two species, White-backed Vulture Gyps africanus and Lappet-faced Vulture Torgus tracheliotus, were recorded only within PAs. We estimate that PAs held c.1,300-3,900 individuals of the five scavenging species combined, including c.1,250-2,900 individuals of two Gyps species. We also present national population estimates for two species: White-backed Vulture (c.1,00o-2,60o birds) and Lappet-faced Vulture (c.160-50o birds). Although sightings were assigned to only three broad distance bands, Distance sampling provided estimates with a level of precision similar to that achieved for linear encounter rates, but as density estimates; a form more readily comparable with results obtained from other survey types.
\end{abstract}

\section{Introduction}

In recent decades vulture populations across Africa have shown rapid declines, variously attributed to deliberate and accidental poisoning (Komen 2009, Ogada and Keesing 2010, Otieno et al. 2010, Ogada and Buij 2011), changes in land use resulting in a decline in food supply (Thiollay 2006a, Virani et al. 2011), and trapping for human consumption or traditional medicines (Mundy et al. 1992, Beilis and Esterhuizen 2005, Thiollay 2006a, Anon 2008, Saidu and Buij 2013). In addition, depletion of wild herbivore populations and improved husbandry of domestic stock have together reduced the availability of carrion in some parts of Africa, further impacting on vulture populations (Thiollay 2006a,b, Western et al. 2009). Use of the non-steroidal anti-inflammatory drug diclofenac, as a veterinary treatment, also poses a potential threat to African vultures, having devastated vulture populations on the Indian subcontinent (Green et al. 2004, Oaks et al. 2004, Anderson et al. 2005), although there is no evidence thus far that it has contributed towards the declines seen in Africa. Nonetheless, despite a long history of human interest in vultures, and 
a widespread recognition of their ecological importance (Ogada et al. 2012, Choisy 2013, Haas and Mundy 2013, Moleón et al. 2014), six out of seven species occurring largely or wholly within Africa are now listed by IUCN as globally threatened (BirdLife International 2013).

As their threat status has changed it has become increasingly necessary to establish baseline indices of abundance, and to monitor subsequent trends. Yet in most African countries, including Uganda, historical changes in vulture populations have been poorly documented. Of eight species recorded in Uganda, two, the Bearded Vulture or Lammergeier Gypaetus barbatus and Egyptian Vulture Neophron percnopterus, bred formerly but are now only vagrants (Carswell et al. 2005). Populations of White-backed Gyps africanus, Rüppell's G. rueppellii, Lappet-faced Torgos tracheliotos and White-headed Vulture Trigonoceps occipitalis were all formerly more widely distributed, but are likely to have fluctuated markedly over the past 50-60 years (Carswell et al. 2005), reflecting the impact of tsetse control measures in the 1960s and exceptionally high levels of poaching pressure on wild herbivore populations in the 1970s. The two remaining species, Hooded Necrosyrtes monachus and Palm-nut Vulture Gypohierax angolensis, are widespread, although the former is concentrated in urban areas. Current threats to vulture species in Uganda, as elsewhere, include land use change and incidental poisoning from illegal baits placed for lions Panthera leo and other large predators, in and around National Parks (Omoya and Plumptre 2011, Uganda Wildlife Authority unpubl. reports).

Despite being large and conspicuous, vultures pose particular survey problems. First, the seven species occurring predominantly in Africa are widely distributed, being native to, and extant within, between six and 39 range states (BirdLife International 2013). Consequently, determining range-wide estimates of population size and rates of change requires that basic, comparable methods are used within multiple range states, some of which lack the resources to undertake large-scale or technically complex surveys. Second, being often thinly distributed but highly clumped, and capable of foraging over large areas, vultures have been counted using a diverse range of methods, with varying degrees of success. They include counts of occupied nests, both at cliff colonies and in wooded savanna (e.g. Borello and Borello 2002, Virani et al. 2010, 2012). Murn et al. (2013), for example, list 15 studies in which tree nests have been counted, an approach that appears straightforward, but requires that all occupied nests are detected, often over an extensive area, and may be complicated by the species' intermittent or protracted breeding cycles (Mundy et al. 1992). A quite different method, involving simultaneous counts at provisioned carcasses in a set of National Parks, has been applied in Uganda (Pomeroy et al. 2004, 2011, 2012), where few recent breeding records exist for most vulture species. However, while this approach yields minimum counts, these are likely to be confounded by extraneous factors, including local game movements and the varying proximity of alternative, natural carcasses. Similarly, surveys at supplementary feeding sites have been used to estimate vulture abundance, although the accuracy of this approach is considered questionable, being potentially subject to a number of biases (Margalida et al. 2011).

African vulture populations have also been surveyed extensively through road counts from slow-moving vehicles, initially by Brown (1972) in East Africa and Thiollay (1977, 1978, 2006a, b,c) in West Africa. This method has been used to determine the effects of land use on encounter rates, as well as to monitor population change; notably, the steep declines evident in West African populations over a period of 30-35 years (Thiollay 2006a,b,c) and in the Masai Mara ecosystem during the 1980s-200os (Virani et al. 2011). A major limitation of the method, however, is that it has typically been used to provide linear indices (birds $100 \mathrm{~km}^{-1}$ ), which are difficult to compare with the density estimates (pairs or birds $100 \mathrm{~km}^{-2}$ ) obtained through nest counts. This limitation has persisted to date, despite the availability of robust, transect-based methods for estimating population densities, applied successfully to other avian taxa, using Distance sampling (Buckland et al. 1993).

Based on annual road counts of raptors in Uganda, made over a six-year period, we sought to establish an index of abundance for six vulture species (Palm-nut, Hooded, White-backed, Rüppell's, Lappet-faced and White-headed Vulture), focusing mainly on the country's four large 
savanna National Parks. In addition to recording encounter rates we noted the distance of each bird to the transect line, and used Distance sampling to estimate population densities. Here, we present encounter rates for the six species, in relation to land use and PA status, and contrast these with rates reported from elsewhere in East and West Africa. We also assess the potential use of Distance sampling as a means of generating vulture density estimates from road surveys, these being more readily comparable with measures obtained through other survey methods, and applicable in any season.

\section{Methods}

During 2008-2013 we recorded the number of vultures seen whilst driving a series of transects along $1,813 \mathrm{~km}$ of roads and tracks, of which $866 \mathrm{~km} \mathrm{(48 \% )} \mathrm{lay} \mathrm{within} \mathrm{protected} \mathrm{areas.} \mathrm{Transects}$ were of 9-122 km in length, and in most cases were surveyed repeatedly over the six-year period, in January ( $84 \%$ of transects) to March. Much of the country receives high levels of sunshine during these months, providing conditions favourable for soaring. Since seven out of 15 egg-laying dates for scavenging species have occurred in November-February (Carswell et al. 2005), our survey coincided with a seasonal increase in breeding activity. Due to logistical constraints the total distance surveyed varied substantially between years, being higher during 2010-2013 than previously (Table 1 ; Appendix $S_{1}$ in the online supplementary material). All surveys were made by experienced observers and, with the exception of one survey of Kidepo Valley National Park, included one or more of the authors. Observer teams normally comprised a recorder and 2-4 observers, with one always on each side of the vehicle. In National Parks, and on some lesser roads outside the parks, two observers watched from outside the vehicle cab, seated on the roof or standing behind the cab, in an open pick-up, where they were able to obtain complete views in all directions, as well as overhead. Most transects were surveyed between oghoo and 17 hoo, when birds were more likely to be in the air, and hence more visible. While most transects were surveyed only once each year, some were surveyed twice (out and back), in which case we used the mean count for each species, since in a small number of cases the recorded distance surveyed in each direction differed slightly. Although we usually stopped when vultures were seen, some birds were identified on the move, and distant birds were sometimes recorded as 'vulture sp.'. During these brief stops we identified those birds already seen. Rarely, additional vultures were seen as a result of stopping, and were included in the count. The time spent stationary was also included as part of the survey duration. The perpendicular distance of each bird from the road or track (when first seen) was estimated and assigned to one of four distance bands, of o-10o, 100-200, 200-500 and $>500 \mathrm{~m}$.

Table 1. The length of transects surveyed in each land use category and year. Survey effort is expressed as the transect length within each land use type, as a percentage of the total distance surveyed. The area of each land use category is expressed as a percentage of the surface area of Uganda.

\begin{tabular}{lcccrr}
\hline \multirow{2}{*}{ Year } & \multicolumn{2}{l}{ Transect length surveyed $(\mathrm{km})$} & & \\
\cline { 2 - 6 } & Natural $^{1}$ & Pastoral & Agricultural & Built & Total \\
\hline 2008 & 784 & 9 & 110 & 0 & 903 \\
2009 & 309 & 0 & 22 & 0 & 331 \\
2010 & 896 & 463 & 568 & 0 & 1,927 \\
2011 & 706 & 394 & 519 & 17 & 1,636 \\
2012 & 776 & 394 & 556 & 12 & 1,738 \\
2013 & 779 & 394 & 507 & 17 & 1,697 \\
Total & 4,250 & 1,654 & 2,282 & 46 & 8,232 \\
$\%$ survey effort & $52 \%$ & $20 \%$ & $28 \%$ & $0.6 \%$ & - \\
$\%$ land area of Uganda & $4 \%$ & $34 \%$ & $41 \%$ & $0.2 \%$ & - \\
\hline
\end{tabular}

${ }^{\top}$ All Natural land lay within Protected Areas. 
The survey made use of networks of tracks in Lake Mburo, Queen Elizabeth, Kidepo Valley and Murchison Falls National Parks, and in Bugungu Wildlife Reserve, a buffer area for Murchison Falls NP. Together, these two PAs are referred to as Murchison Falls Conservation Area. Counts were also made on public roads from Entebbe to Mbarara, Entebbe to Murchison Falls CA, and from Soroti to southern Karamoja, in north-east Uganda. Each transect was assigned to one of four land use categories: natural (within PAs); pastoral (vegetation almost entirely natural, but with wild herbivores replaced largely by domestic stock); agricultural; and built. Most pastoral transects included small areas of agricultural land and vice-versa, and both contained human settlements, mainly small trading centres. We also recorded transect length $(\mathrm{km}$, by odometer); start and end time and hence mean vehicle speed; mean altitude (from topographical maps); mean annual rainfall (from Government of Uganda 1967); human population density (UBOS 2012) and woodland cover (open grassland, lightly wooded, heavily wooded, forest). A small proportion of transects within PAs were predominantly woodland, dominated by Acacia and Combretum spp. 'Woodland' was defined as $>20 \%$ tree canopy cover, after Pratt and Gwynne (1977).

\section{Data analysis}

\section{Encounter rates:}

We used generalised linear mixed models (GLMMs) to investigate the relationship between the number of vultures detected from each transect, and the following potential explanatory variables: transect length, land use category, woodland cover, altitude, annual rainfall and the presence of 'outside' observers. For consistency between land use types, and to standardise methods for any future surveys, we excluded sightings of birds more than $500 \mathrm{~m}$ from the transect line. Since our data included repeated surveys of the same transects in different years we entered 'transect' and 'year' as random terms in all models. We derived minimal models through elimination of the least significant fixed variables, and selected final models from those with the lowest Akaike Information Criterion (AIC) score.

In each model the response variable was either the presence or the number of individuals of a given species or species group: of Gyps vultures (White-backed and Rüppell's Vulture) or scavenging vultures (Hooded, White-backed, Rüppell's, Lappet-faced and White-headed Vulture). Since most transects yielded zero or few vulture sightings the distribution of each response variable was highly skewed. We therefore examined habitat associations using two model structures. First, using data from all transects, we identified explanatory variables associated with the presence/ absence of a given species or group, specifying a binomial error distribution. In the second model we restricted the dataset to cases where at least one individual of the target species or group had been detected, and specified a Poisson error distribution. GLMMs were fitted using the glmer function in the lme4 package in R (3.0.1; R Development Core Team 2009). The R plot, qqnorm and hist functions were used to determine whether final models reasonably met with model assumptions (Crawley 2013). To determine encounter rates in relation to land use we used data from all transects within land use categories in which the target species had been recorded at least once, and specified a Poisson error distribution. Fitted values were derived from final models using the $\mathrm{R}$ fitted function, and used to estimate the mean $( \pm \mathrm{SE})$ individuals encountered $100 \mathrm{~km}^{-2}$ in each land use category. All probabilities are quoted as two-tailed.

\section{Density and population estimates:}

Densities were estimated using Distance V6.0, Release 2 (Thomas et al. 2010). Where excessive heaping of detection distances occurred, wider intervals were selected to offset this. All detection data were right-truncated to $500 \mathrm{~m}$, since the distances of birds sighted beyond this band were not recorded. Four model types were fitted (half-normal, hazard-rate, uniform and negative-exponential), each with cosine, simple polynomial and hermite polynomial adjustments. The negative-exponential 
model, regarded as a model of last resort, was only considered if goodness of fit (tested by chi-square) suggested that no other model provided a satisfactory fit (Buckland et al. 1993). Selection of the most appropriate detection function was based on minimum AIC. To estimate densities of a target species within different strata we first determined whether the detection function varied significantly across the strata, using a chi-square test. Where no significant differences were found we used Multiple Covariates Distance Sampling (MCDS; Thomas et al. 2010), stratifying accordingly (e.g. by land use). We also used this approach where the total number of detections for a given species was low; that is, we pooled sightings of two or more species (e.g. Gyps species) and then stratified by species in MCDS.

To estimate a species' population size within each land use category we multiplied the estimated density for a given category by its estimated area within Uganda. Land use areas were derived from those of 13 land cover types given in UBOS (2012), up to 2005. We assigned these land cover types to the four broad land use categories used here, as follows: commercial farmland and cultivated land identified by UBOS (2012) was assigned to 'agricultural'; bushland, grassland and all woodland areas thought to be grazed by domestic herds (including those grazed illegally within PAs) to 'pastoral'; open, non-forested habitat within PAs to 'natural'; and built up land to 'built'. However, because the level of survey effort applied within 'built' land was insufficient to yield meaningful estimates of encounter rates or densities, this category was excluded from the analyses. In some cases area estimates for PAs were adjusted to take account of the proportion of land thought to be grazed by domestic livestock in each PA. Overall, our national area estimates were as follows: agricultural, 99,703 km²; pastoral, 83,002 km²; natural, 9,573 km²; and built, $366 \mathrm{~km}^{2}$. The total area within these four land use categories $\left(192,644 \mathrm{~km}^{2}\right)$ comprised $80 \%$ of the surface area of Uganda $\left(241,550 \mathrm{~km}^{2} ;\right.$ UBOS 2012). The remaining $20 \%$ of land consisted of habitats within which vultures were likely to have been sparse or absent: water bodies, wetlands, tropical forest and plantations.

\section{Results}

\section{Encounter rates}

During 2008-2013 we made 784 vulture detections over a combined distance of 8,232 km (Table 1 ). Six species were seen in sufficient numbers to determine encounter rates and densities; a seventh, Egyptian Vulture, was seen only once. The number of vultures counted varied markedly in relation to land use, most species being recorded mainly, or only, in protected areas (Figure 1 ). Using GLMMs we investigated the effects of this and other potential explanatory variables on the number of vultures encountered on each transect. Although vehicle speed differed significantly between transects on public roads (mean: $33.1 \mathrm{~km} \mathrm{hr}^{-1}$ ) and in protected areas $\left(24.0 \mathrm{~km} \mathrm{hr}^{-1}\right.$; Mann-Whitney $\left.U_{8,15}=23.50 ; P=0.006\right)$, the importance of recording time of day at the start and end of each transect was not fully appreciated by the field teams. Hence, these variables were recorded too infrequently to be included in the models.

Binomial GLMMs showed that Rüppell's and White-headed Vultures were significantly more likely, and Hooded Vultures less likely, to be detected from transects within PAs than elsewhere (Table 2). Collectively, the five scavenging species were also more likely to be detected from transects within PAs and in pastoral land, than in agricultural land. Within these land use categories White-backed, Rüppell's and White-headed Vultures were less likely, and Lappet-faced Vultures more likely, to be detected in heavily wooded areas than in grassland or lightly wooded habitats, perhaps reflecting differences in their detectability, rather than their abundance. GLMMs fitted with a Poisson error distribution showed that on transects where Hooded or White-headed Vulture were detected, the number of individuals counted was significantly lower within PAs than elsewhere. In contrast, the number of Palm-nut Vultures counted was higher along transects within PAs than on transects in agricultural land.

The likelihood of detecting Gyps species, and the number of individuals of Gyps and of scavenging vulture species detected, was significantly higher where 'outside' observers were deployed 

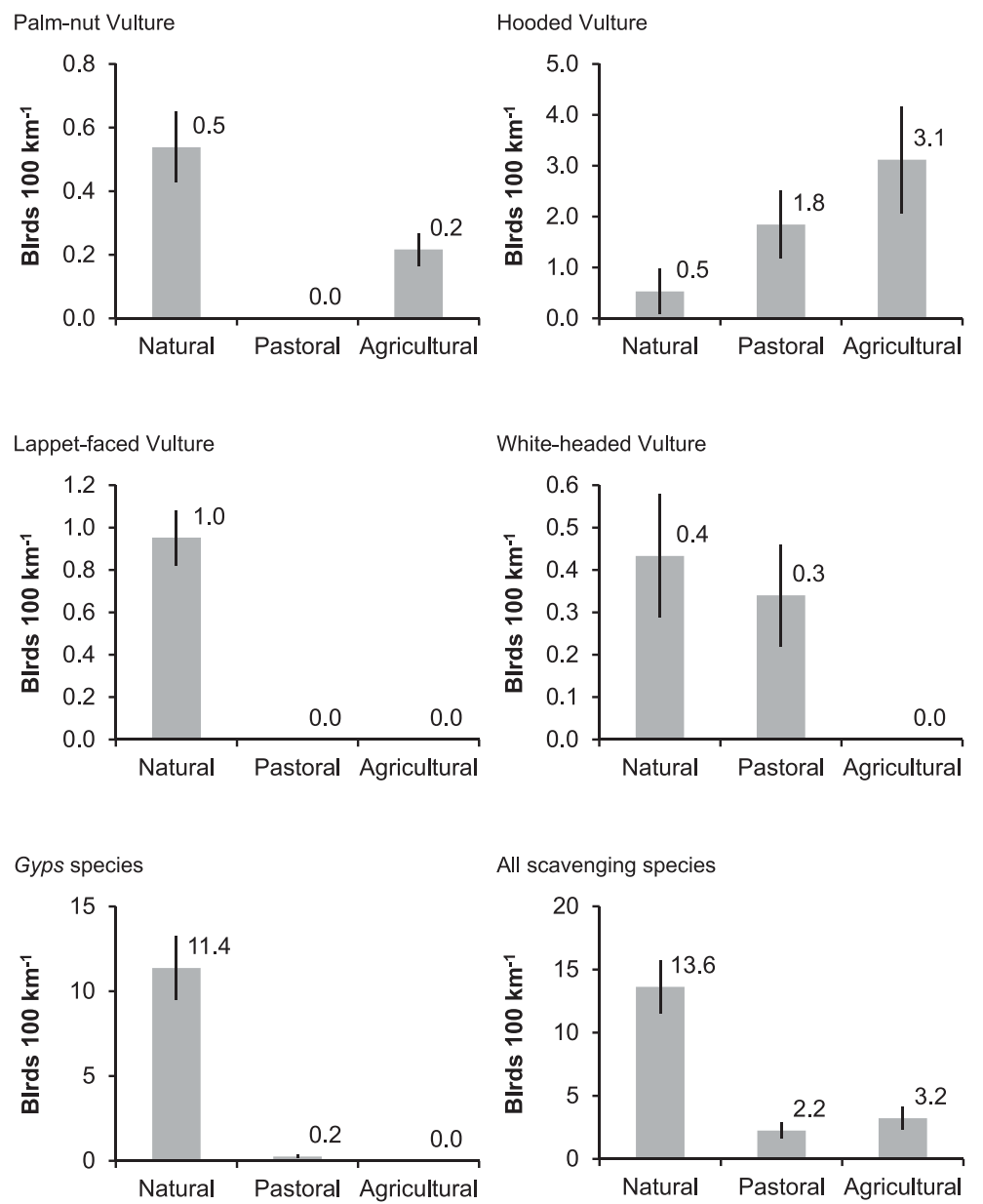

Figure 1 . Species encounter rates (mean $\pm_{1} \mathrm{SE}$ individuals encountered $100 \mathrm{~km}^{-1}$ ) in relation to land use category, calculated from GLMM fitted values.

(Table 2). Note, however, that outside observers were deployed more often within PAs $(82 \%$ of transect-surveys) than elsewhere ( $13 \%$ of transect-surveys), potentially confounding the relationship between protected area status and vulture abundance. To investigate this effect we used a GLMM model to determine whether the presence of outside observers increased the likelihood of detecting members of the five scavenging species, which search mainly while soaring. First, we specified a binomial error distribution to examine the likelihood of encountering at least one individual of the five species, on transects surveyed within protected areas, and in the presence/ absence of outside observers. We then restricted the dataset to transects on which at least one individual vulture was detected, and used a Poisson error distribution to determine whether the number of individuals detected was linked to the presence/absence of outside observers. These models showed, respectively, that the presence of outside observers did not influence the likelihood of detecting at least one scavenging vulture individual, but had a significant positive effect on the number of birds detected (Effect $=0.97 \pm 0.196 ; z=4.964 ; P<0.001$ ). Fitted values from the Poisson model indicate that the mean encounter rate was $55 \%$ higher when outside observers were deployed $\left(29.4 \pm 5.64 \mathrm{SE}\right.$ birds $\left.100 \mathrm{~km}^{-1}\right)$, than when they were absent (18.9 $\pm 5.98 \mathrm{SE}$ birds $100 \mathrm{~km}^{-1}$ ). 
Table 2. Summary of generalised linear mixed models examining associations between potential explanatory variables and: the likelihood of detecting at least one individual from a transect (Binomial models); the number of individuals detected (Poisson models; restricted to transects from which at least one individual was detected). H. wooded = Heavily wooded; L. wooded = Lightly wooded.

\begin{tabular}{|c|c|c|c|c|c|c|c|c|}
\hline Model & Error term & $n^{1}$ & Term & $z$ & $P$ & Condition & Effect & $\pm \mathrm{SE}$ \\
\hline \multirow{5}{*}{$\begin{array}{l}\text { 1. Palm-nut } \\
\text { Vulture }\end{array}$} & \multirow[t]{2}{*}{ Binomial } & \multirow[t]{2}{*}{159} & Intercept & -4.38 & $<0.001$ & - & -6.66 & 1.522 \\
\hline & & & Transect length & 2.56 & 0.010 & - & 0.04 & 0.016 \\
\hline & \multirow[t]{3}{*}{ Poisson } & \multirow[t]{3}{*}{19} & Intercept & -1.58 & 0.113 & - & -0.69 & 0.441 \\
\hline & & & Transect length & $4 \cdot 36$ & $<0.001$ & - & 0.01 & 0.002 \\
\hline & & & PA status & 2.09 & 0.037 & Protected & 0.96 & 0.457 \\
\hline \multirow{9}{*}{$\begin{array}{l}\text { 2. Hooded } \\
\text { Vulture }\end{array}$} & \multirow[t]{3}{*}{ Binomial } & \multirow[t]{3}{*}{159} & Intercept & -3.57 & $<0.001$ & - & -3.11 & 0.872 \\
\hline & & & Transect length & 2.38 & 0.017 & - & 0.02 & 0.009 \\
\hline & & & PA status & -1.92 & 0.055 & Protected & -1.85 & 0.965 \\
\hline & \multirow[t]{6}{*}{ Poisson } & \multirow[t]{6}{*}{24} & Intercept & -0.49 & 0.619 & - & -0.76 & 1.529 \\
\hline & & & Transect length & 2.06 & 0.039 & - & 0.01 & 0.003 \\
\hline & & & PA status & $-3 \cdot 72$ & $<0.001$ & Protected & -1.44 & 0.387 \\
\hline & & & Woodland & -4.12 & $<0.001$ & Lightly wooded & -2.27 & 0.552 \\
\hline & & & & -3.29 & 0.001 & Heavily wooded & -1.67 & 0.509 \\
\hline & & & Altitude & 2.79 & 0.005 & - & 0.01 & 0.001 \\
\hline \multirow{9}{*}{$\begin{array}{l}\text { 3. White-backed } \\
\text { Vulture }\end{array}$} & \multirow[t]{5}{*}{ Binomial } & \multirow[t]{5}{*}{136} & Intercept & 3.12 & 0.002 & - & 9.62 & 3.084 \\
\hline & & & Transect length & 2.19 & 0.028 & - & 0.03 & 0.011 \\
\hline & & & Woodland & -2.33 & 0.019 & L. wooded-Forest & -4.44 & 1.908 \\
\hline & & & Outside observer(s) & 2.78 & 0.006 & Present & 3.15 & 1.136 \\
\hline & & & Rainfall & -3.26 & 0.001 & - & -0.01 & 0.003 \\
\hline & \multirow[t]{4}{*}{ Poisson } & \multirow[t]{4}{*}{37} & Intercept & 2.89 & 0.004 & - & $3 \cdot 52$ & 1.215 \\
\hline & & & Transect length & 3.29 & $<0.001$ & - & 0.01 & 0.003 \\
\hline & & & Outside observer(s) & 4.88 & $<0.001$ & Present & 0.99 & 0.202 \\
\hline & & & Rainfall & -2.56 & 0.011 & - & -0.01 & 0.001 \\
\hline \multirow{8}{*}{$\begin{array}{l}\text { 4. Rüppell's } \\
\text { Vulture }\end{array}$} & \multirow[t]{3}{*}{ Binomial } & \multirow[t]{3}{*}{159} & Intercept & -3.49 & 0.001 & - & $-4 \cdot 37$ & 1.252 \\
\hline & & & PA status & 2.30 & 0.022 & Protected & 3.11 & 1.351 \\
\hline & & & Woodland & -2.29 & 0.022 & H. wooded-Forest & -2.09 & 0.912 \\
\hline & \multirow[t]{5}{*}{ Poisson } & 15 & Intercept & 0.53 & 0.596 & - & 0.86 & 1.619 \\
\hline & & & Land use & $3 \cdot 36$ & $<0.001$ & Pastoral & 3.29 & 0.979 \\
\hline & & & Woodland & 2.89 & 0.004 & H. wooded-Forest & 1.35 & 0.465 \\
\hline & & & Altitude & -2.95 & 0.003 & - & -0.01 & 0.002 \\
\hline & & & Rainfall & 2.85 & 0.005 & - & 0.01 & 0.002 \\
\hline 5. Gyps species & Binomial & 136 & Intercept & 2.60 & 0.009 & - & $9 \cdot 55$ & 3.668 \\
\hline & & & Transect length & 1.78 & 0.075 & - & 0.03 & 0.014 \\
\hline & & & Outside observer(s) & 2.39 & 0.017 & Present & 2.55 & 1.067 \\
\hline & & & Rainfall & $-3 \cdot 47$ & 0.001 & - & -0.01 & 0.004 \\
\hline & Poisson & 39 & Intercept & 0.62 & 0.422 & - & 1.46 & 0.144 \\
\hline & & & Transect length & 0.01 & 0.004 & - & 2.30 & 0.021 \\
\hline & & & Outside observer(s) & 1.02 & 0.199 & Present & 5.11 & 0.000 \\
\hline 6. Lappet-faced & Binomial & 137 & Intercept & 2.17 & 0.029 & - & 11.64 & $5 \cdot 359$ \\
\hline Vulture & & & Transect length & $3 \cdot 32$ & 0.001 & - & 0.03 & 0.007 \\
\hline & & & Woodland & 2.61 & 0.009 & Forest & 8.93 & 3.419 \\
\hline & & & Outside observer(s) & 2.02 & 0.043 & Present & 1.80 & 0.889 \\
\hline & & & Rainfall & -2.81 & 0.005 & - & -0.02 & 0.007 \\
\hline & Poisson & 17 & Intercept & 0.64 & 0.521 & - & 0.19 & 0.292 \\
\hline & & & Transect length & $3 \cdot 46$ & 0.001 & - & 0.01 & 0.002 \\
\hline 7. White-headed & Binomial & 159 & Intercept & -1.93 & 0.053 & - & -2.60 & 1.347 \\
\hline Vulture & & & Transect length & $3 \cdot 33$ & $<0.001$ & - & 0.02 & 0.006 \\
\hline & & & PA status & 1.81 & 0.071 & Protected & 1.98 & 1.096 \\
\hline & & & Woodland & -3.17 & 0.001 & L. wooded-Forest & -3.17 & 1.000 \\
\hline & Poisson & 11 & Intercept & 5.15 & $<0.001$ & - & 1.95 & 0.378 \\
\hline & & & PA status & -2.76 & 0.006 & Protected & -1.20 & 0.436 \\
\hline
\end{tabular}


Table 2. Continued.

\begin{tabular}{|c|c|c|c|c|c|c|c|c|}
\hline Model & Error term & $n^{1}$ & Term & $z$ & $P$ & Condition & Effect & $\pm \mathrm{SE}$ \\
\hline \multirow{9}{*}{$\begin{array}{l}\text { 8. Scavenging } \\
\text { species }^{2}\end{array}$} & \multirow[t]{5}{*}{ Binomial } & \multirow[t]{5}{*}{158} & Intercept & -2.61 & 0.009 & - & -2.62 & 1.004 \\
\hline & & & Transect length & 2.57 & 0.010 & - & 0.03 & 0.010 \\
\hline & & & Land use & 2.99 & 0.003 & Natural & 2.96 & 0.987 \\
\hline & & & & 0.34 & 0.733 & Pastoral & 0.38 & 1.129 \\
\hline & & & Woodland & -2.93 & 0.003 & H. wooded-Forest & -2.38 & 0.811 \\
\hline & \multirow[t]{4}{*}{ Poisson } & \multirow{4}{*}{58} & Intercept & 1.00 & 0.327 & - & 3.06 & 0.002 \\
\hline & & & Transect length & 0.01 & 0.003 & - & 2.25 & 0.024 \\
\hline & & & Woodland & -1.94 & 1.280 & Forest & -1.52 & 0.129 \\
\hline & & & Outside observer(s) & 0.78 & 0.139 & Present & $5 \cdot 54$ & 0.000 \\
\hline
\end{tabular}

${ }^{1}$ Number of cases. One case $=$ one transect surveyed in one year.

${ }^{2}$ Pooled sightings of Hooded, White-backed, Rüppell's, Lappet-faced and White-headed Vulture.

Using GLMM fitted values, mean encounter rates within the four savanna PAs surveyed varied substantially between species, the encounter rate for White-backed Vulture being some eight times that of Rüppell's, and 10-25 times that of each of the three remaining scavenging species. In all cases, mean encounter rates recorded for scavenging vultures were lower than those reported from recent road surveys in Kenya and West Africa (Table 3).

\section{Density and population estimates}

With a density of c.17 birds $100 \mathrm{~km}^{-2}$, White-backed Vultures were the most abundant species on natural land, followed by Palm-nut Vulture, at c. 7 birds $100 \mathrm{~km}^{-2}$ (Table 4). White-backed Vultures were thus 5-7 times more abundant in this land use type than any other scavenging vulture, including its congener, Rüppell's Vulture (2.4 birds $\left.100 \mathrm{~km}^{-2}\right)$. Note, however, that the detection pattern for these two Gyps species differed; $42 \%$ of White-backed Vultures were detected in the furthest distance band from the transect $(200-500 \mathrm{~m})$, compared with only $9 \%$ of Rüppell's Vultures $\left(\chi_{2}^{2}=30.00 ; P<0.001\right)$. This suggests that White-backed Vultures were either more sensitive to disturbance or more easily detected at that distance. Alternatively, there may have been a tendency for observers to identify the more distant individuals as the commoner of the two Gyps species. Accordingly, combined densities for Gyps species are also given (Table 4).

Hooded and White-headed Vultures were the least abundant species in protected areas, at a density of $<$ I bird $100 \mathrm{~km}^{-2}$ ). White-headed, along with Rüppell's Vulture, were also recorded on pastoral land at densities similar to those estimated for protected areas. Estimates within pastoral land, however, were based on just seven sightings of each species and hence produced wide confidence limits, varying by a factor of c.27 (upper/lower CL). In contrast, Hooded Vultures appeared to be nine and 14 times more abundant on pastoral and agricultural land, respectively, than in PAs.

Based on overall densities within natural land, the four PAs appeared to support a combined total of c.1,000-3,000 individuals of the five scavenging species, and a further $300-1,000$ Palm-nut Vultures. Area estimates for open, natural land within Uganda's remaining PAs suggest that its protected area network is likely to hold c.I,300-3,900 scavenging vultures, and c.400-1,200 Palm-nut Vultures (Table 5). Since White-backed and Lappet-faced Vultures were recorded only in PAs, our estimates for these species (c.1,000-2,600 and 160-500 birds, respectively) represent national population estimates. We were unable to determine national population sizes for the four remaining species, each of which occurred within 2-3 land use types, and in three cases were detected only rarely in at least one of these. Since pastoral and agricultural land together accounts for c. $76 \%$ of the surface area of Uganda, the chance sighting of just 1-2 additional or fewer individuals in either land use type would have had a substantial impact on national population estimates. Consequently, the density estimates generated had extremely wide confidence limits, such that we were unable to derive meaningful population estimates for these species in these land use types. 
Table 3. Mean $( \pm \mathrm{SE})$ vulture numbers detected $100 \mathrm{~km}^{-1}$ during road surveys within protected areas in Uganda, Kenya and West Africa. Estimates for Uganda were calculated from GLMM fitted values.

\begin{tabular}{lccc}
\hline Species & Uganda $(2008-2013)^{1}$ & Kenya $(2004-2005)^{2}$ & West Africa $(2003-2004)^{3}$ \\
\hline Palm-nut Vulture & $0.6 \pm 0.12$ & \multicolumn{2}{l}{0.0} \\
Egyptian Vulture & 0.0 & 0.0 & 0.0 \\
Hooded Vulture & $0.5 \pm 0.45$ & $2.3 \pm 0.80$ & $16.2 \pm 6.0$ \\
White-backed Vulture 5 & $10.0 \pm 1.96$ & - & $15.4 \pm 8.1$ \\
Rüppell's Vulture & $1.3 \pm 0.33$ & - & $2.8 \pm 0.0$ \\
Gyps species & $11.4 \pm 1.81$ & $21.3 \pm 3.18$ & 18.2 \\
Lappet-faced Vulture & $1.0 \pm 0.13$ & $4.4 \pm 0.96$ & $1.1 \pm 0.4$ \\
White-headed Vulture & $0.4 \pm 0.12$ & $1.4 \pm 0.55$ & $1.3 \pm 0.6$ \\
Scavenging species & $13.5 \pm 2.14$ & 29.4 & 36.8 \\
\hline
\end{tabular}

${ }^{1}$ This study.

${ }^{2}$ Road surveys in the Masai Mara, Kenya, January-May 2004-2005: from Virani et al. (2011).

3 Road surveys in Burkina Faso, Mali and Niger (Thiollay 2006a).

4Two birds seen; excluded from analysis.

5Excludes a single high count. If included, mean $\pm \mathrm{SE}=20.5 \pm 9.99$.

${ }^{6}$ Hooded, White-backed, Rüppell's, Lappet-faced and White-headed Vulture.

\section{Discussion}

The five globally threatened vulture species surveyed here are widespread throughout Africa, and include colonial, cliff-nesting species (Rüppell's Vulture) as well as solitary and loosely colonial tree nesters, among which the proportion of adults actually breeding may vary between species, sites and years (Mundy et al. 1992). Consequently, many of the range states involved are likely to lack the funding or expertise required to mount surveys of nest occupancy, on a scale large enough to yield robust population indices. While nest surveys indicate the size of the breeding population, and hence yield an important measure of the local status of these long-lived, slow-breeding species, the existence of a non-breeding component within the population, capable of replacing nest- or territory holders, could initially mask declines among breeding individuals. Conversely, monitoring the abundance of non-breeding individuals could provide an early warning of any decline in the breeding population (Margalida et al. 2011).

Table 4. Vulture density estimates (birds $100 \mathrm{~km}^{-2}$ ) derived through Distance sampling, in relation to land use.

\begin{tabular}{llrllll}
\hline Land use & Species & $n^{1}$ & Detection function & Adjustments & Density $^{2}$ & (CLs) \\
\hline Natural & Palm-nut Vulture & 57 & Uniform & SP3 & 7.2 & $(4.0-12.9)$ \\
(PA) & Hooded Vulture & 24 & Uniform & None & 0.6 & $(0.2-1.5)$ \\
& White-backed Vulture & 456 & Half normal & None & 16.8 & $(10.4-27.0)$ \\
& Rüppell's Vulture & 63 & Uniform & SP3 & 2.4 & $(1.1-5.4)$ \\
& Gyps species & 519 & Uniform & SP3 & 20.0 & $(13.0-30.7)$ \\
& Lappet-faced Vulture & 42 & Neg. exponential & None & 3.0 & $(1.7-5.3)$ \\
Pastoral & White-headed Vulture & 21 & Half normal & None & 0.9 & $(0.5-2.0)$ \\
& Hooded Vulture & 29 & Half normal & None & 5.5 & $(2.3-12.9)$ \\
& Rüppell's Vulture & 7 & Half normal & None & 1.5 & $(0.3-8.2)$ \\
Agricultural & White-headed Vulture & 7 & Neg. exponential & None & 1.5 & $(0.3-8.3)$ \\
& Palm-nut Vulture & 6 & Half normal & None & 1.6 & $(0.8-3.4)$ \\
& Hooded Vulture & 62 & Half normal & None & 8.4 & $(3.5-19.9)$ \\
\hline
\end{tabular}

${ }^{1}$ Number of detections.

${ }^{2}$ Birds $100 \mathrm{~km}^{-2}$.

3SP: Simple polynomial. 
Table 5. Population estimates (individuals; CLs in brackets) within the four protected areas surveyed, and within all PAs combined.

\begin{tabular}{|c|c|c|c|c|c|}
\hline & Lake Mburo NP & Murchison Falls CA & Queen Elizabeth NP & Kidepo Valley NP & All Protected Areas ${ }^{1}$ \\
\hline Palm-nut Vulture & $27(15-48)$ & $279(156-498)$ & $133(75-239)$ & $96(53-171)$ & $688(385-1,231)$ \\
\hline Hooded Vulture & $2(1-6)$ & $22(8-59)$ & $10(4-28)$ & $7(3-20)$ & $54(20-146)$ \\
\hline White-backed Vulture & $62(39-100)$ & $651(405-1,048)$ & $312(194-502)$ & $223(139-359)$ & $1,608(1,000-2,587)^{[2]}$ \\
\hline Rüppell's Vulture & $9(4-20)$ & $94(43-208)$ & $45(20-99)$ & $32(15-71)$ & $232(105-513)$ \\
\hline Gyps species & $74(48-114)$ & $775(505-1,190)$ & $371(242-570)$ & $266(173-408)$ & $1,914(1,247-2,938)$ \\
\hline Lappet-faced Vulture & II $(6-20)$ & $115(65-205)$ & $55(31-98)$ & $39(22-70)$ & $284(160-505)^{[2]}$ \\
\hline White-headed Vulture & $3(2-7)$ & $37(18-76)$ & $17(8-36)$ & $13(6-26)$ & $90(44-187)$ \\
\hline Scavenging species & $88(51-152)$ & $919(538-1,595)$ & $440\left(25^{8}-763\right)$ & $315(185-547)$ & $2,269(1,328-3,938)$ \\
\hline All species & $114(67-201)$ & $1,198(695-2,094)$ & $572(332-1,002)$ & $410(238-717)$ & $2,957(1,713-5,168)$ \\
\hline
\end{tabular}

${ }^{1}$ Including natural land within Uganda's remaining PAs.

${ }^{2}$ Since White-backed and Lappet-faced Vulture were detected only within PAs, these figures represent national population estimates for Uganda. 
In many instances, as here, road surveys may offer a more straightforward, practical alternative, providing a means of generating both population indices and density estimates, comparable between range states. Furthermore, road surveys include breeding adults, non-breeding adults and immatures, and are therefore more comprehensive than nest counts. They are, however, subject to a number of biases, particularly with respect to the routes surveyed, although this is more serious when making population estimates than for monitoring. Care should be taken to avoid sampling densely occupied areas in close proximity to nest colonies, and to consider the effects of breeding seasonality. In this study, for example, adults incubating or brooding nestlings will have been missed, leading to a degree of underestimation. More generally, trend estimates from visual surveys may be strongly influenced by spatial variation in food availability or the presence of competitors, and are hence likely to be less accurate than estimates obtained from detailed demographic models (Margalida et al. 2011).

\section{Encounter rates and densities: which are more precise?}

Over a six-year period we surveyed 4,250 km of roads and tracks within protected areas, in which four of the six vulture species were more common than elsewhere. Although these transects yielded a large number of encounters (669), the level of uncertainty associated with mean encounter rates was high in the case of scarce species, including Rüppell's, White-headed and (in protected areas) Hooded Vulture. For example, we detected a mean of 1.3 ( \pm 0.33 SE) Rüppell's Vultures $100 \mathrm{~km}^{-1}$, yielding $95 \%$ CLs of \pm 0.65 . This indicates that a future survey would be unable to detect a change in the encounter rate of less than $50 \%$, with statistical confidence. With the exception of Hooded Vulture, for which CLs were extremely wide, equivalent estimates for the remaining species were similar to, or lower than that of Rüppell's: 54\% (White-headed), 39\% (Palm-nut), 38\% (Whitebacked) and $25 \%$ (Lappet-faced Vulture). Levels of precision achieved using Distance sampling were generally lower than those associated with linear encounter rates. Therefore, in most cases it would be possible to detect a smaller decline in a species' encounter rate than in its density, with statistical confidence. Two exceptions were Hooded and White-headed Vulture, for which declines in density (of at least $67 \%$ and $44 \%$ ) would be more easily detectable than declines in encounter rate.

Recording the perpendicular distance of each bird or group of birds from the transect line provided added value, enabling us to estimate each species' density and population size, particularly within protected areas. Note, however, that Distance sampling requires that several key assumptions are met (Buckland et al. 1993). First, the distance between the observer and the bird should be measured accurately. In this study we assigned all detections to one of three wide distance bands, thereby minimising the proportion of detections subject to inaccurate distance estimation. Second, each bird should be detected before it moves in response to the observer (or vehicle). Although this assumption seems likely to have been met on most occasions, there remains the possibility that soaring vultures may have adjusted their flight path in response to the vehicle, prior to detection. Here again, the adoption of wide distance bands may have partially mitigated such an effect. Third, all birds present at zero distance from the transect (i.e. directly overhead) must be detected. Although the deployment of outside observers appears to have raised the proportion of birds detected, it was not practicable to have such observers on busy public roads, and there remains the possibility that a small proportion of birds directly overhead were missed, resulting in under-estimation of the true density. Fourth, to minimise double-counting the observer must be moving more quickly along the transect than the subject. Whereas the mean vehicle speed in natural areas was $24.0 \mathrm{~km} \mathrm{hr}^{-1}$, mean cross-country speeds of Gyps species (in the Serengeti) have been estimated at 47-56 km hr-1 (Pennycuick 1973). Although in most cases the birds recorded here are unlikely to have been flying parallel to the transect, it is possible that some individuals were recorded more than once on the same transect.

The routes surveyed should have provided a representative sample of each of Uganda's four main savanna National Parks. In practice, however, survey effort was uneven, Kidepo Valley NP being under-represented due to cost constraints. Ideally, our transects should also have been located independently of features likely to influence vulture densities (Buckland et al. 1993). Clearly, the routes taken by public roads and tracks within protected areas do not meet this 
assumption, since they avoid difficult terrain, are subject to repeated disturbance and, in the case of public roads, have a positive association with human habitation. These factors are likely to have led to an underestimation of vulture densities in pastoral and agricultural areas, with the exception of Hooded Vulture, given its association with (roadside) human settlements. These points strongly influence the accuracy of density estimates, but are less important when the data are used for monitoring, provided that the same routes are surveyed each time.

\section{Potential refinements}

As an alternative to annual counts, surveys repeated at longer intervals (e.g. of 3-4 years), might prove more cost-effective, and statistically more powerful, as a way of detecting trends in vulture abundance. Furthermore, the application of Distance sampling in this survey was only partially successful, in two respects. First, in most cases MCDS did not improve the precision of density estimates sufficiently to enable us to generate national population estimates for species detected in pastoral and agricultural land, where very few detections were made. Clearly, generating meaningful estimates for Palm-nut, Rüppell's and White-headed Vulture in these land use categories would require increased survey effort, perhaps by a factor of four or five. Second, the precision of density estimates made in natural areas was also low, but might be improved by assigning detections to finer distance bands, e.g. five $100 \mathrm{~m}$ bands, and by using an electronic rangefinder.

\section{Vulture abundance in Uganda and elsewhere}

Our findings demonstrate the importance of protected areas, or of the 'natural' habitats and herbivore populations that they support, for the conservation of vultures in Uganda, and probably in much of tropical Africa. Collectively, the five scavenging vulture species were detected from four to six times more frequently within PAs than in agricultural and pastoral land, and two species (White-backed and Lappet-faced Vulture), were recorded nowhere else during the course of the survey. Nevertheless, pastoral land is of particular importance to vulture populations in Uganda, being almost nine times more extensive than natural land, and providing corridors between the savanna parks. Also, pastoral land is likely to change less in coming years than agricultural areas, which were important only for Hooded and Palm-nut Vultures (Table 4).

\section{Gyps species:}

Our findings suggest that Uganda holds c.1,000-2,60o White-backed Vultures (0.4-1.0\% of the global population; BirdLife International 2013), and that its protected areas hold c.1,200-2,900 Gyps individuals, including c.100-500 Rüppell's Vultures. Gyps encounter rates within protected areas in Uganda were just 50-60\% of those reported from West Africa (Thiollay 2006a) and the Masai Mara, Kenya, during the non-migration season (Virani et al. 2011). Furthermore, the density of White-backed Vulture in Uganda's protected areas (10-27 birds $100 \mathrm{~km}^{-2}$ ) was much lower than that reported from the Masai Mara National Reserve (c.72-286 birds $100 \mathrm{~km}^{-2}$; Virani et al. 2011) and from protected areas in Swaziland (c.38-208 birds $100 \mathrm{~km}^{-2}$; Monadjem and Garcelon 2005), but was similar to density estimates for Kruger National Park, South Africa (Murn et al. 2013).

A possible explanation for Uganda's low density of Gyps vultures, relative to that of the Masai Mara, is the depletion, during the mid-1970s, of its wild herbivore populations (R. Lamprey pers. comm. 2013), which remain well below the levels recorded in the 196os (Lamprey et al. 2003). The paucity of breeding records of Gyps vultures in Uganda in recent decades (R. Ssemmanda and D. Pomeroy pers. obs.) suggests that each is part of a metapopulation covering a much larger area. This is supported by a recent observation of large numbers of vultures drifting northwards, at a great height over Lake Mburo National Park (Pomeroy 2008). 


\section{White-headed and Lappet-faced Vultures:}

Uganda is likely to support a population of c.160-500 Lappet-faced Vultures (c.2-6\% of the global population; BirdLife International 2013), while its protected area network may support c.30-150 White-headed Vultures, with additional birds present on pastoral land. The encounter rate for White-headed Vulture (0.4 birds $100 \mathrm{~km}^{-1}$ ) was only c. $30 \%$ of that recorded in West Africa and Kenya (1.3-1.4 birds $100 \mathrm{~km}^{-1}$; Thiollay 2006a, Virani et al. 2011), while Lappetfaced Vultures were detected at very similar rates in this study and in West Africa (1.0-1.1 birds $100 \mathrm{~km}^{-1}$ ), but at 4-5 times this rate in the Masai Mara (Virani et al. 2011). Consequently, even within protected areas White-headed and Lappet-faced Vultures were recorded at extremely low densities ( $<2$ birds and $2-5$ birds $100 \mathrm{~km}^{-2}$, respectively), broadly consistent with densities reported from protected areas in South Africa (Hitchins 1980), Swaziland (Monadjem and Garcelon 2005) and Tanzania (Pennycuick 1976).

Being more solitary, territorial, better at searching over wide areas (Spiegel et al. 2013) and more likely to arrive early at carcasses (Mundy et al. 1992), White-headed and Lappet-faced Vulture are more adept at finding and exploiting a wider range of carcass sizes, and hence are less dependent on large herbivore concentrations (Pennycuick 1976). The few nests observed of these species in Uganda have been in tree species that are plentiful, so that nest site availability is unlikely to limit their numbers.

\section{Hooded Vulture:}

Hooded Vultures are sparsely distributed in Uganda's protected areas, where the encounter rate ( 0.5 birds $100 \mathrm{~km}^{-1}$ ) was much lower than that recorded in the Masai Mara (2.3 birds $100 \mathrm{~km}^{-1}$; Virani et al. 2011) and in West African PAs (c.16 birds $100 \mathrm{~km}^{-1}$; Thiollay 2006a). While Uganda's protected area network thus appears to hold just c.20-150 Hooded Vultures, its more extensive areas of pastoral and agricultural land may support much larger populations. However, as noted above, our estimates are likely to have been inflated by the species' close association with human habitation, and hence with Uganda's road network. The biggest population of this species is in Kampala, where numbers have declined from about 400 in the early 1970 s to just over 100 in 2014 (Pomeroy 1975, Ssemmanda and Pomeroy 2010, M. Kibuule pers. comm., authors' unpubl. data).

\section{Palm-nut Vulture:}

Palm-nut Vulture is thought to be increasing in Uganda's protected areas (Pomeroy in press), which appear to support c.390-1,230 birds, at a density of $4-13$ birds $100 \mathrm{~km}^{-2}$. This is much lower than the exceptionally high densities reported by Thiollay (1998) in Cote d'Ivoire in 1996 and 1972 , of 11 and 13 pairs in a 2,000 ha study site; equivalent to $110-130$ birds $100 \mathrm{~km}^{-2}$.

\section{Conclusions}

In view of the large number of range states occupied by Africa's threatened vulture species (BirdLife International 2013) there is clearly a need to develop simple, robust field methods yielding comparable measures of their abundance. To date, tree nest counts have been used as a measure of population density in at least 15 studies, mainly in southern Africa (Murn et al. 2013), while road surveys have been used more widely in West Africa and, to a lesser extent, in East Africa, providing linear indices of abundance. Here, we demonstrate that Distance sampling, even when based on relatively wide distance bands, provided estimates that were broadly comparable with the densities derived from nest counts, and in two cases were more precise than those associated with linear encounter rates. The latter varied significantly between protected and unprotected land, by a factor of $4-6$, and were sufficiently precise (in four cases) to enable future road surveys to detect declines of $25-54 \%$ within Uganda's protected areas. 


\section{Supplementary Material}

The supplementary materials for this article can be found at journals.cambridge.org/bci

\section{Acknowledgements}

We are particularly grateful to the Uganda Wildlife Authority for granting permission to make counts in protected areas, and for making available their most experienced rangers. Several volunteers from NatureUganda acted as recorders. Roger Skeen kindly provided the data for Kidepo Valley National Park. We are also especially grateful to Will Cresswell for providing guidance on statistical analyses, and to Eric Rexstad, who advised on the Distance sampling analysis. The cost of field work was generously covered by The Peregrine Fund (USA) and the Royal Society for the Protection of Birds (UK).

\section{References}

Anderson, M. D., Piper, S. E. and Swan, G. E. (2005) Non-steroidal anti-inflammatory drug use in South Africa and possible effects on vultures. S. Afr. J. Sci. 101: 112-114.

Anon. (2008) Traditional medicine demand threatens vultures in southern Africa. Vulture News 58: 77-79.

Beilis, N. and Esterhuizen, J. (2005) The potential impact on Cape Griffon Gyps coprotheres populations due to the trade in traditional medicine in Maseru, Lesotho. Vulture News 53: 15-19.

BirdLife International (2013). Datazone. Available at: http://www.birdlife.org/ datazone/home

Borello, W. D. and Borello, R. M. (2002) The breeding status and colony dynamics of Cape Vulture Gyps coprotheres in Botswana. Bird Conserv. Internatn. 12: 79-97.

Brown, L. (1972) African birds of prey. London, UK: Collins.

Buckland, S. T., Anderson, D. R., Burnham, K. P. and Laake, J. L. (1993) Distance sampling: estimating abundance of biological populations. London, UK: Chapman and Hall.

Carswell, M., Pomeroy, D., Reynolds, J. and Tushabe, H. (2005) The bird atlas of Uganda. Oxford, UK: British Ornithologists' Club \& British Ornithologists' Union.

Choisy, J.-P. (2013) The vultures at the crossroads of biodiversity, politics, tourism, the environment and agriculture. Vulture News 63: 15-39.

Crawley, M. J. (2013) Statistics: An introduction using $R$. Chichester, UK: J. Wiley \& Sons, Ltd.
Government of Uganda (1967) Atlas of Uganda. $2^{\text {nd }}$ ed. Entebbe, Uganda: Department of Lands and Surveys.

Green, R. E., Newton, I., Shultz, S., Cunningham, A. A., Gilbert, M., Pain, D. J. and Prakash, V. (2004) Diclofenac poisoning as a cause of vulture population declines across the Indian subcontinent. J. Appl. Ecol. 41: 793-800.

Haas, D. and Mundy, P. (2013) Vultures revered in time and place. Vulture News 63: 4-14.

Hitchins, P. M. (1980). Breeding populations of vultures in the Hluhluwe-Umfolozi game reserve complex. Lammergeyer 30: 26-31.

Komen, L. (2009) Namibia - vultures killed deliberately and accidentally. African Raptors 2: 13 .

Lamprey, R. H., Buhanga, E. and Omoding, J. (2003) A study of wildlife distributions, wildlife management systems, and options for wildlife-based livelihoods in Uganda. For International Food Policy Research Institute and USAID, Kampala, Uganda.

Margalida, A., Oro, D., Cortés-Avizanda, A., Heredia, R. and Donázar, J. A. (2011) Misleading population estimates: Biases and consistency of visual surveys and matrix modelling in the endangered Bearded Vulture. PLOS ONE 6(10): e26784. doi:10.1371/ journal.pone.0026784.

Moleón, M., Sánchez-Zapata, J. A., Margalida, A., Carrete, M., Owen-Smith, N. and Donázar, J. A. (2014) Humans and scavengers: evolution of interactions and ecosystem services. BioScience 64: 394-403. 
Monadjem, A. and Garcelon, D. K. (2005) Nesting distribution of vultures in relation to land use in Swaziland. Biodiv. Conserv. 14: 2079-2093.

Mundy, P., Butchart, D., Ledger, J. and Piper, S. (1992) The vultures of Africa. South Africa: Acorn Books.

Murn, C., Combrink, L., Ronaldson, G. S., Thompson, C. and Botha, A. (2013) Population estimates of three vulture species in Kruger National Park, South Africa. Ostrich: J. Afr. Ornithol. 84: 1-9.

Oaks, J. L., Gilbert, M., Virani, M. Z., Watson, R. T., Meteyer, C. U., Rideout, B. A., Shivaprasad, H. L., Ahmed, S., Chaudhry, M. J. I., Arshad, M., Mahmood, S., Ali, A. and Khan, A. A. (2004) Diclofenac residues as the cause of vulture population declines in Pakistan. Nature 427: 630-633.

Ogada, D. and Keesing, F. (2010) Decline of raptors over a three-year period in Laikipia, central Kenya. J. Raptor Res. 44: 129-135.

Ogada, D. L. and Buij, R. (2011) Large declines of the Hooded Vulture Necrosyrtes monachus across its African range. Ostrich 82: 101-113.

Ogada, D. L., Torchin, M. E., Kinnaird, M. F. and Ezenwa, V. O. (2012) Effects of vulture declines on facultative scavengers and potential implications for mammalian disease transmission. Conserv. Biol. 26: 453-460.

Omoya, E. O. and Plumptre, A. J. (2011) An assessment of availability and use of carbofuran and other agro-vet chemicals used to poison lions, around Queen Elizabeth Conservation Area (QECA) and in Kampala, Uganda. Unpublished report.

Otieno, P. O., Lalah, J. O., Virani, M., Jondiko, I. O. and Schramm, K. (2010) Carbofuran and its toxic metabolites provide forensic evidence for Furadan exposure in vultures (Gyps africanus) in Kenya. Bull. Envir. Contam. Toxicol. 84: 536-544.

Pennycuick, C. J. (1973) The soaring flight of Vultures. Sci. Amer. 229: 102-109.

Pennycuick, C. J. (1976) Breeding of the lappetfaced and white-headed vultures (Torgos tracheliotus Forster and Trigonoceps occipitalis Burchell) on the Serengeti Plains, Tanzania. E. Afr. Wildl. J. 14: 67-84.

Pomeroy, D. (1975) Birds as scavengers of refuse in Uganda. Ibis 117: 69-81.
Pomeroy, D. (2008) Raptor migrations in western Uganda - spring 2007 and 2008. Gabar 19: 68-70.

Pomeroy, D. (in press) Twenty four years of presence-absence data show no overall decline of vultures in Uganda. Vulture News. Pomeroy, D., Dranzoa, C., Anyii, P., Friday, T., Kaphu, G., Sande, E. and Seifert, L. (2004) A vulture count in Uganda and a suggestion to other vulture-counters. Vulture News 50: 29-33.

Pomeroy, D., Byaruhanga, A., Kaphu, G., Opige, M., Masiko, M. and Lutuk, B. (2011) A second count of vultures at carcasses in Uganda, and a revised proposal for a standardized method. Vulture News 60: 15-21.

Pomeroy, D., Kaphu, G., Nalwanga, D., Ssemmanda, R., Loyuk, B., Opeto, A. and Matsiko, M. (2012) Counting vultures at provisioned carcasses. Vulture News 62: 25-32.

Pratt, D. J. and Gwynne, M. D., eds. (1977) Rangeland management and ecology in East Africa. London, UK: Hodder and Stoughton.

R Development Core Team (2009) R: A language and environment for statistical computing. Available at: <www.r-project.org/>

Saidu, Y. and Buij, R. (2013) Traditional medicine trade in vulture parts in northern Nigeria. Vulture News 65: 4-14.

Spiegel, O., Getz, W. M. and Nathan, R. (2013) Factors influencing foraging search efficiency: why do scarce Lappet-faced Vultures outperform ubiquitous White-backed Vultures? Amer. Nat. 181: DOI 10 1086/670009.

Ssemmanda, R. and Pomeroy, D. (2010) Scavenging birds of Kampala: 1973-2009. Scopus 30: 26-31.

Thiollay, J.-M. (1977) Distribution saisonnière des rapaces diurnes en Afrique Occidentale. Oiseau R.F.O. 47: 253-294.

Thiollay, J.-M. (1978) Les migrations de rapaces en Afrique Occidentale: adaptations écologiques aux fluctuations saisonnières de production des écosystèmes. Terre Vie 32: 89-133.

Thiollay, J.-M. (1998) Long-term dynamics of a tropical savanna bird community. Biodiv. Conserv. 7: 1291-1312.

Thiollay, J.-M. (2006a) The decline of raptors in West Africa: long-term assessment and the role of protected areas. Ibis 148: 240-254. 
Thiollay, J.-M. (2006b) Large bird declines with increasing human pressure in savanna woodlands (Burkina Faso). Biodiv. Conserv. 15: 2085-2108.

Thiollay, J.-M. (2006c) Severe declines of large birds in the northern Sahel of West Africa: a long-term assessment. Bird Conserv. Internatn. 16: 353-365.

Thomas, L., Buckland, S. T., Rexstad, E. A., Laake, J. L., Strindberg, S. Hedley, S. L., Bishop, J. R. B., Marques, T. A., Burnham, K. P. (2010) Distance software: design and analysis of distance sampling surveys for estimating population size. J. Appl. Ecol. 47: 5-14.

UBOS (2012) Statistical abstract. Kampala, Uganda: Uganda Bureau of Statistics.

Virani, M., Kirui, P., Monadjem, A., Thomsett, S. and Githiru, M. (2010) Nesting status of African White-backed Vulture Gyps africanus in the Masai Mara National Reserve, Kenya. Ostrich 81: 205-209.

Virani, M. Z., Kendall, C., Njoroge, P. and Thomsett, S. (2011) Major declines in the abundance of vultures and other scavenging raptors in and around the Masai Mara ecosystem, Kenya. Biol. Conserv. 144: 746-752.

Virani, M., Monadjem, A., Thomsett, S. and Kendall, C. (2012) Seasonal variation in breeding Ruppell's Vultures Gyps ruepellii at Kwenia, southern Kenya and implications for conservation. Bird Conserv. Internatn. 22: 26o-269.

Western, D., Russell, S. and Cuthill, I. (2009) The Status of wildlife in protected areas compared to non-protected areas of Kenya. PLoS ONE 4(7), e6140.doi:10.1371/journal. pone.0006140.

\section{DEREK POMEROY*}

Department of Biological Sciences, Makerere University, PO Box 7298 Kampala, Uganda.

\section{PHIL SHAW}

School of Biology, Harold Mitchell Building, University of St Andrews, Fife, KY 169 9TH, UK. Institute of Tropical Forest Conservation, Mbarara University of Science and Technology, PO Box 44, Kabale, Uganda.

\section{MICHAEL OPIGE}

NatureUganda, PO Box 27034 Kampala, Uganda.

\section{GEORGE KAPHU}

Uganda Wildlife Authority, PO Box 3530 Kampala, Uganda.

\section{DARCY L. OGADA and MUNIR Z. VIRANI}

The Peregrine Fund, 5668 West Flying Hawk Lane, Boise, Idaho 83709, USA.

National Museums of Kenya, Ornithology Section, Box 40658, oo1oo Nairobi, Kenya.

*Author for correspondence; e-mail derek@imul.com

Received 19 February 2014; revision accepted 27 July 2014;

Published online 12 December 2014 